\title{
Evaluation of Current Situation in Career Development and Training of Teaching Physician
}

\author{
Ye Yang ${ }^{1, \dagger}$, Qin Yi Zhang ${ }^{1}$, Jia Yang Xia ${ }^{2}$, Xiao Ling Han², Xu Zhou ${ }^{2}$, Sheng Jie Xu', Wei Liu ${ }^{2, *}$, \\ Wei Lin Sang, , Yan Li Li ${ }^{1, *}$, Su Fang Wu, ${ }^{1, *}$ \\ ${ }^{1}$ Department of Obstetrics and Gynecology, Shanghai General Hospital affiliated to Shanghai Jiao Tong University School of Medicine, \\ Shanghai, P. R. China \\ ${ }^{2}$ Department of Education, Shanghai General Hospital Affiliated to Shanghai Jiao Tong University School of Medicine, Shanghai, P. R. China \\ ${ }^{3}$ Department of Orthopedics, Shanghai General Hospital Affiliated to Shanghai Jiao Tong University School of Medicine, Shanghai, P. R. \\ China
}

\section{Email address:}

sukura5203@sina.com (Ye Yang),459868191@qq.com (Qin Yi Zhang), xiajy117@163.com (Jia Yang Xia), 13371989275@163.com (Xiao Lin Han),zhouxu_0108@163.com (Xu Zhou),xu_xdc@163.com (Sheng Jie Xu),wei.liu@shgh.cn(Wei Liu), weilin.sang@shgh.cn (Wei Lin Sang), liecho121@126.com (Yan Li Li), wusufang73@163.com (Su Fang Wu)

*Corresponding author

${ }^{\dagger}$ Ye Yang is the first author.

\section{To cite this article:}

Ye Yang, Qin Yi Zhang, Jia Yang Xia, Xiao Ling Han, Xu Zhou, Sheng Jie Xu, Wei Liu, Wei Lin Sang, Yan Li Li, Su Fang Wu. Evaluation of Current Situation in Career Development and Training of Teaching Physician. Journal of Family Medicine and Health Care.

Vol. 7, No. 2, 2021, pp. 30-38. doi: 10.11648/j.jfmhc.20210702.12

Received: May 3, 2021; Accepted: May 15, 2021; Published: May 21, 2021

\begin{abstract}
Background: Extreme competition for grant funding or publications to gain career promotion in an affiliated hospital has outsized negative effects on doctor to gain career promotion in China these years. This research seeks to explore the relationships between evaluation of a teaching physician and their actual aptitude towards career promotion. Methods: This study was offered to all teachers and standardized residency training students at Shanghai General Hospital affiliated to Shanghai Jiao Tong University. A web-based survey was conducted to identify individuals' aptitude to teaching physician. A total of 240 participants entered and finished the study, including 140 teachers and 100 standardized residency training students. The questions consisted of how teaching physician is assessed, the percentage of clinical, scientific work and teaching grant funding/awards/publications of teaching physician, as well as attitude towards training in teaching. Results: Teaching physicians tried to satisfy scientific research or grant funding/awards/publications requirements and failed to apply time on teaching, thus affect the teaching quality. Teaching training can serve as an approach to ensure career growth and advancement in medical education. Teaching physicians should be equipped with teaching skills and educational administration in teaching curriculum development. Conclusions: We recommend the outstanding teaching physician should not only be equipped with clinical skills, but also be full of teaching enthusiasm and methods as well as improved quality of teaching through training.
\end{abstract}

Keywords: Teaching Physicians, Career Promotion, Training, Grant Funding/Awards/Publications

\section{Introduction}

Frequently, traditional medical schools put emphasize on the basic medical knowledge. Even though in recent years, PBL (Problem-Based Learning), CBL (Case-Based Learning), and simulated teaching have been carried out, most of them are still limited, which lack of actual clinical training like making diagnosis, treatment and grasping surgical skills.
Graduate medical education is the first step in training physicians capable of critical skills, knowledge, independent patient care, uncertainty biomedical ethics, and gaining doctor-patient relationship at bedside in clinical training [1]. These complex endeavors are conducted by the first-line clinicians in the teaching hospital. However, in China, the clinical doctors also undertake the task of medical scientific research and teaching work at the same time. Due to the 
potentially overwhelming of the above work, attendance at a substantial teaching remains more difficult. Even more, in recent years, the hyper-competition for scientific publications and grant funding in an affiliated hospital has become a debated discussion in China these years and has outsized negative effects on doctors to gain career promotion [2]. Doctors spent a certain amount of effort and proportion in their daily work and tried to satisfy the scientific research requirements, thus failed to apply time on teaching and affect the teaching quality. This situation needs to be changed, therefore building a successful professional career in the physicians who are specialized in teaching is rewarding but challenging, especially in the dynamic and competitive environment of today's modern medical circumstances.

Career opportunities including development of career plans, focusing on career goals, implementation of career steps, and evaluation of career success. Ross. E believed that one of the first issues was to resolve the need to better define the career expectations for individuals [3]. With today's growing focus on the translation of basic science into clinical practice, the demand for a teaching physician is likely to grow. Thus, teaching physician was specially categorized in Shanghai General Hospital affiliated to Shanghai Jiao Tong University, which has led to multiple choices of career paths. The other career paths categories are clinical physician, scientific physician, and combined clinical-scientific physician, which are mainly focus on whose corresponding specialized regions. Nevertheless, no matter what type the doctor is, his main responsibility is to undertake clinical work. The hospitals both provide promotion paths and require regular assessments for teaching physicians. In addition to responsible for clinical medical diagnosis and treatment in daily work, at the same time teaching physicians should focus on teaching which required they should be equipped with improved quality of teaching methods and excellent teaching enthusiasm.

In this article, we made a questionnaire about the current situation of teaching physicians and their career development models that framed key elements associated with the curriculum evaluations, recommendations, interactions, memberships in organizations continuing medical education. We also discuss the steps involved in percentage in clinical work, scientific research, grant funding/awards/publications, and establishing methods to training in academic professional presentations. The primary aim of this study was to characterize the status of career promotion of teaching physicians in China to equip doctors with required teaching skills. Secondary aim was to assess the aptitude from students and doctors to teaching physicians and identify performance on teaching physicians.

\section{Methods}

\subsection{Interview Administration}

Our study included web-based questionnaires of the 140 teachers and 100 standardized residency training students in Shanghai General Hospital affiliated to Shanghai Jiao Tong University. The surveys were distributed from 2019 and January to August of 2020. A total of 240 participations in the survey were anonymous and voluntary. Each participant completed a survey online in a single session. Responses were collected via Wen Juan Xing (https://www.wjx.cn), and exported as an excel file, recruitment was conducted by online analysis, respectively. Data analysis was performed only on received responses.

\subsection{Survey Frame}

The entire survey can be found in Table 1. A 24-item interview protocol questions were developed regarding the current teaching physicians in graduate medical education. Participants were asked to quantify their opinion and make choice. We investigated attitudes towards quality of teaching physician and their teaching climate, educational doctor career specialty as well as about factors that have influenced their choice. We also tracked doctors' actual state in clinical, scientific, and teaching work as well as their attitudes towards grant funding/awards/publications.

Table 1. Survey for: Evaluation of current situation in career development and training of teaching physician.

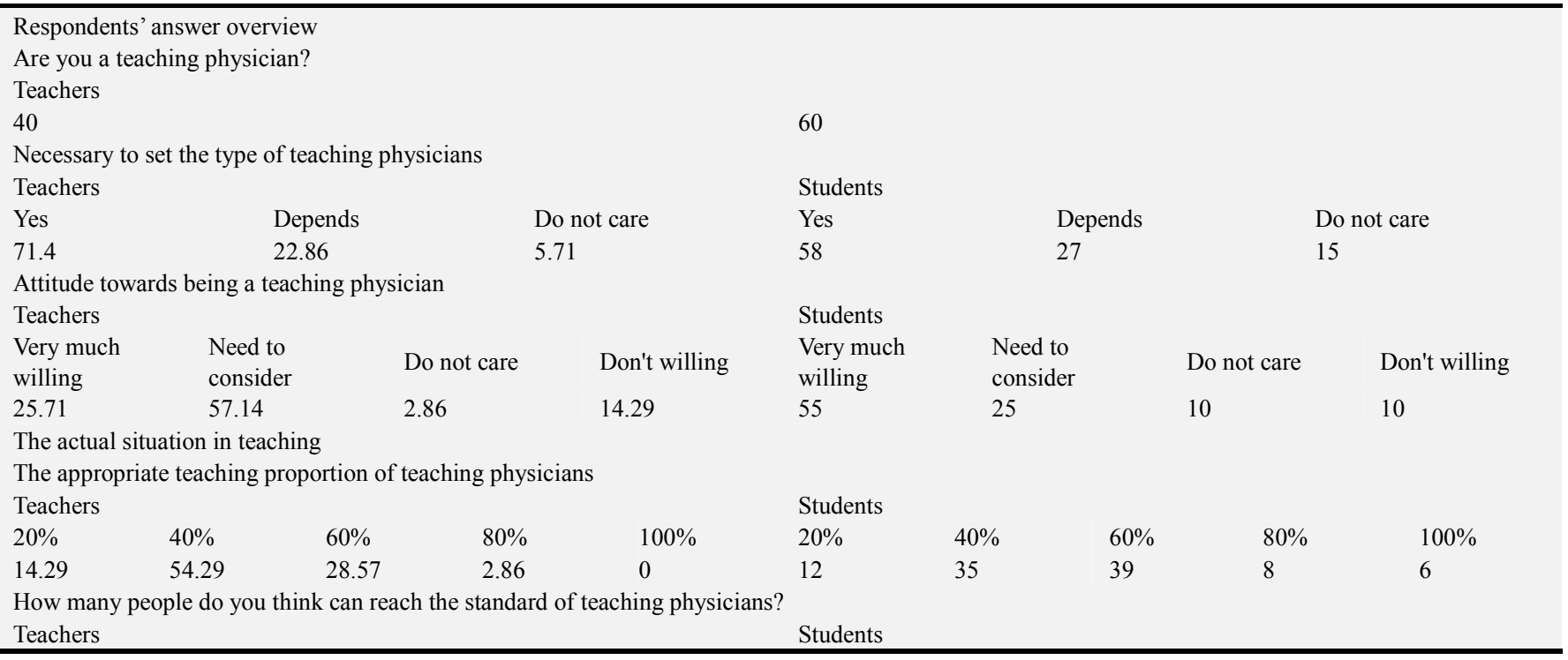




\begin{tabular}{lllllllll}
\hline $20 \%$ & $40 \%$ & $60 \%$ & $80 \%$ & $100 \%$ & $20 \%$ & $40 \%$ & $60 \%$ & $80 \%$ \\
71.43 & 11.43 & 2.86 & 11.43 & 2.86 & 15 & 34 & 29 & $100 \%$ \\
\hline
\end{tabular}

How many teaching physicians do not meet the requirements, while their purpose of being a teaching physician is to obtain career promotion?

Teachers

\begin{tabular}{l|lllllllllll}
$0 \%$ & $20 \%$ & $40 \%$ & $60 \%$ & $80 \%$ & $100 \%$ & $0 \%$ & $20 \%$ & $40 \%$ & $60 \%$ & $80 \%$ & $100 \%$ \\
5.71 & 31.43 & 31.43 & 14.29 & 17.14 & $0 \%$ & 8 & 31 & 29 & 24 & 8 & 0
\end{tabular}

Clinical work

What is your attitude towards the clinical work and its proportion in the work of teaching physicians?

Teaching physician should engage in teaching instead of clinical work

$\mathrm{He} / \mathrm{She}$ cannot teach if he/she was not equipped with clinical knowledge or surgical skills.

$\mathrm{He} / \mathrm{She}$ was occupied with the clinical work, how much he/she can teach depends on time.

The actual situation in teaching is:

I am fully engaged in teaching work instead of clinical work.

No matter how busy the clinical work is, I can teach students as requested.

$\begin{array}{ll}\text { Teachers } & \text { Students } \\ 8.57 & 13 \\ 85.71 & 61 \\ 5.71 & 26\end{array}$

Although I know the importance of teaching, since I was engaged in clinical work, how much I can teach depends on time.

The clinician's responsibility is to conduct medical treatment or operation, teaching occupy much of time, I basically do not teach.

Scientific research

The appropriate science research proportion of teaching physicians

$\begin{array}{ll}\text { Teachers } & \text { Students }\end{array}$

$\begin{array}{lllllllllll}0 \% & 20 \% & 40 \% & 60 \% & 80 \% & 100 \% & 0 \% & 20 \% & 40 \% & 60 \% & 80 \% \\ 14.29 & 68.57 & 14.29 & 2.86 & 0 & 8 & 38 & 29 & 100 \%\end{array}$

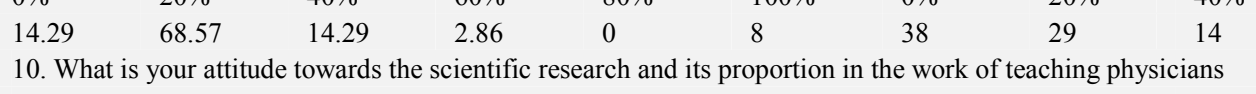

Teaching physician should engage in teaching instead of scientific research.

Teachers Students

Teaching physician should also be equipped with the scientific research ability in order to teach

11.43

Although scientific research is important, the reason why he/she choose to be a teaching physician is to safe effort on scientific research.

Scientific research is efficient, whether he/she is a teaching physician or not, he/she must focus on scientific research.

Grant funding/awards/publications

11. The reason doctors only focus on teaching grant funding/awards/publications, but not actually do teaching work is that

$\mathrm{He} / \mathrm{She}$ is willing to teach, however he/she is occupied with grant funding/awards/publications in order to gain career promotion.

The purpose to be a teaching physician is for career promotion, so grant funding/reward/publication is the most important.

Teachers

12. Is it reasonable to use teaching grant funding/awards/publications as evaluation of teaching physicians?

Very reasonable

Since there is no other evaluation way, grant funding/awards/publications are fair in evaluation

Grant funding is reasonable, others are not

Publications are reasonable, others are not

Both were unreasonable

13. How to evaluate the grant funding/awards/publications in the assessment of teaching physicians?

It depends on the level of the grant funding/awards/publications

We should put emphasize on the actual teaching problems rather than take the level of grant

funding/awards/publications as the only evaluation.

$\begin{array}{ll}\text { Teachers } & \text { Students } \\ 20 & 14 \\ 80 & 86\end{array}$

14. Among the teaching doctors around you, the percentage of physicians only focus on grant funding/awards/publications, while do not actually engage in teaching work?

\begin{tabular}{|c|c|c|c|c|c|c|c|c|c|c|c|}
\hline \multicolumn{6}{|c|}{ Teachers } & \multicolumn{6}{|c|}{ Students } \\
\hline $0 \%$ & $20 \%$ & $40 \%$ & $60 \%$ & $80 \%$ & $100 \%$ & $0 \%$ & $20 \%$ & $40 \%$ & $60 \%$ & $80 \%$ & $100 \%$ \\
\hline 14.29 & 37.14 & 28.57 & 11.43 & 8.57 & 0 & 12 & 42 & 26 & 10 & 6 & 4 \\
\hline
\end{tabular}

Elements of teaching physician

15. How satisfied are you with your integration through teaching?

Greatly promoted

Have a positive effect, but need to be improved 
Devote to the teaching work, Good at getting along with students, benefit students from clinical knowledge

Good at writing grant funding/publications or gain awards

Good at speeches and teaching competitions

17. The effect of teaching physician in the educational team building

Educational physician is important to guide the educational team.

Scientific research is more important than teaching.

Limited number of teaching physician has less impact on team building.

18. Attitude towards the teaching concept?

Update the teaching concept regularly to bring students new and meaningful teaching experience

Update the teaching concept is one thing, while actually teaching is another thing.

Although they know updating the teaching concept is important, they are occupied with the clinical work, they still follow the old idea.

There is no need to update the teaching concept.

Training in teaching

19. What is the most important in teaching currently

Training as well as updating the teaching concept and methods

Grant funding/awards/publications

Clinical knowledge and surgical skills.

Theoretical knowledge is more important than actual clinical work.

20. Attitude towards educational physician training

Conduct frequently training combined with new teaching concept and methods

How much he/she participates in the course depends on time, since he/she was occupied with clinical work

There is no need to train, at the time they do the clinical work, they teach.

It does not matter to him/her, he/she don't care.

21. Attitude towards training in teaching

It is very helpful to participate in training course.

97.14

2.86

0

Teachers

34.29

40

25.71

Teachers

74.29

8.57

17.14

Teachers

57.14

2.86

34.29

2.86

Teachers

68.57

22.86

5.71

2.86

Teachers

37.14

8.57 promotion

Whether I can participate in training course depends on time, since I was occupied with clinical work. I don't want to take part in training, it's a waste of time.

22. Attitude towards the time and frequency requirements for teaching courses

Regular frequency lectures are essential. I take it seriously to prepare clinical teaching and courses. Theoretical knowledge is combined with actual clinical work, there is no need to arrange special courses.

Although I think it does not matter, however, in order to meet the hospital's requirements, I will still follow the frequency, but cannot ensure the quality.

How much I can teach depends on my time.

Although I think it is essential, however due to the clinical and scientific research cost time, I cannot follow the frequency.

Although I think it is essential, however due to the clinical and scientific research cost time, I cannot ensure the quality.

Teaching appearance

23. Is teaching related to the teacher's appearance, teaching state and speaking tone

Yes, teaching is related to the teacher's appearance, teaching state and speaking tone

Yes, however speaking tone can be trained

It does not matter, theoretical and clinical knowledge is more important.

It does not matter

24. What is the difference between a teaching physician and general teacher?

Teaching physician is both a teacher and doctor, who should be equipped with good theoretical and clinical knowledge.

Teaching physician is busier than teacher, who should ensure patients' safety during teaching

The teaching physician is the same as a general teacher

The teaching physician is the same as a general doctor.

The general teacher is good at teaching than a teaching physician

0

Teachers

51.43

8.57

2.86

8.57

Teachers

40

40

20

0

Teachers

74.29

17.14

5.71

2.86
98

2

Students

79

13

Students

51

26

23

0

Students

49

0

48

3

Students

47

42

6

Students

30

40

0

Students

70

10

0

0 


\section{Results}

\subsection{Respondents'Answer Overview}

We received 240 responses of the survey from the teaching hospital, including 140 teachers and 100 students, 56 (40\%) were teaching physicians. A total of $100(71.43 \%)$ physicians and $58 \%$ students felt it is necessary to set the type of teaching physician, only $5.71 \%$ physicians and $15 \%$ students do not care if it is necessary to set the type of teaching physician. However, while refer to aspiration to be a teaching physician, $25.71 \%$ teachers and $55 \%$ students very much willing, $57.14 \%$ teachers and $25 \%$ students need consideration, $14.29 \%$ teachers and $10 \%$ students do not willing.

\subsection{The Actual Situation Teaching}

$54.29 \%$ teachers and $35 \%$ students indicated that the appropriate teaching proportion of teaching physicians should be $40 \%, 28.57 \%$ teachers and $39 \%$ students responded the proportion should be $60 \% .51 .43 \%$ of the teachers thought no matter how busy the clinical work is, they can teach students as requested. $42.86 \%$ believed although they know the importance of teaching, since they are engaged in clinical work, how much they can teach depends on time. Only $11.43 \%$ teachers and $16 \%$ students thought $80 \%$ of teaching physicians meet the requirement of teaching physician, $71.43 \%$ teachers and $15 \%$ students regarded proportion is $20 \%$. Correspondingly, $31.43 \%$ teachers and about $30 \%$ students indicated $20-40 \%$ of teaching physicians do not meet the requirements, their purpose of being an educational doctor is to obtain career promotion, which might be related to teaching physician paid more attention to scientific or teaching grant funding/awards/publications for their career development instead of actually engage in teaching work.

\subsection{The Proportion of Clinical Work of Teaching Physician}

It is important to concentrate one's efforts as much as possible in her/his specialist clinical region. Good teaching was generally conducted along with experienced clinical technology, therefore feedback was as below: doctors cannot teach if they are not equipped with clinical knowledge or surgical skills (85.71\% teachers and $61 \%$ students), doctors should engage in teaching instead of clinical work $(8.57 \%$ teachers and $13 \%$ students), how much I can teach depends on time since I am occupied with the clinical work $(5.71 \%$ teachers and $26 \%$ students).

\subsection{The Proportion of Scientific Research Work of Teaching Physician}

Scientific research is an important evaluation standard of doctor's career promotion in our institution. $68.57 \%$ teachers and $29 \%$ students from programs thought the appropriate science research proportion of teaching physicians should be $20 \%$. Regarding the proper proportion of scientific research in the work of the teaching physician, we collected feedback: Teaching physician should also be equipped with the scientific research ability to teach students $(77.14 \%$ teachers and $54 \%$ students), teaching physician should engage in teaching instead of scientific research $(11.43 \%$ teachers and $28 \%$ students), scientific research is efficient, whether I am a teaching physician or not, I must focus on scientific research (8.57\% teachers and $11 \%$ students), although scientific research is important, the reason I choose to be a teaching physician is to safe effort on scientific research $(2.86 \%$ teachers and $7 \%$ students).

\subsection{Teaching Grant Funding/Awards/Publications}

Teaching specialized doctor aptitude assessments also included academic advancement such as grant funding/awards/publications or certificates of accomplishments. However, in recent years, there existed the phenomenon that doctors only apply and focus on teaching grant funding/awards/publications, but do not actually teach. In our questionnaire, $71.42 \%$ teachers and $78 \%$ students agreed with the statement "He/She is willing to teach, however, he/she is occupied with grant funding/awards/publications in order to gain career promotion.", whereas $28.57 \%$ teachers and $22 \%$ students reported the purpose to be educational doctors is for career promotion, so grant funding/reward/publication is the most important. As to reply for the reasonable use of teaching grant funding/awards/publications as evaluation of teaching physicians, $48.57 \%$ teachers and $46 \%$ students felt since there is no other evaluation way, grant funding/awards/publications are fair in evaluation, $22.86 \%$ teachers and 19\% students believed it is very reasonable. The majority $(80 \%$ teachers and $86 \%$ students) regarded that they should put emphasize on the actual teaching problems rather than take the level of grant funding/awards/publications as the only evaluation. $20 \%$ teachers and 14\% students thought it depends on the level of the grant funding/awards/publications. However, $11.43 \%$ teachers and $10 \%$ students reported $60 \%$ teaching physicians only focus on grant funding/awards/publications, while do not actually engage in teaching work.

\subsection{Elements of Teaching Physician}

Educational doctors should incorporate both professional and personal considerations. Regarding physician's attitude towards integration through teaching, 34.29\% greatly promoted, $57.14 \%$ have a positive effect, but need to be improved. 97.14\% teachers and 98\% students thought devoted to the teaching work, good at getting along with students, benefit students from clinical knowledge are the most important qualities of an educational doctor. Respect to opinion of the effect of teaching physician in the educational team building: $40 \%$ teachers agreed with the statement "Scientific research is more important than teaching", while $79 \%$ students believed educational physician is important to guide the educational team. Furthermore, $74.29 \%$ teachers and $51 \%$ students indicated teaching physicians should update the teaching concept regularly to bring students new and meaningful teaching experience, $17.14 \%$ teachers and $23 \%$ students regarded although they know updating the teaching concept is important, they are occupied with the clinical work, 
when they do actually teach, they follow the old idea.

\subsection{Attitude Towards Training Teaching}

Training education fellowships provide a foundation of the course in surgical education each year. Fellowships provide the opportunity to obtain and participate in formal training combined with research and teaching. The quality of teaching was predominantly assessed using evaluations of teaching. $57.14 \%$ teachers and $49 \%$ students considered training as well as updating the teaching concept and methods is the most important in teaching currently, another $34.29 \%$ teachers and $48 \%$ students regarded clinical knowledge and surgical skills are the most important in teaching. Then we conducted an investigation about training in teaching, $68.57 \%$ teachers and $47 \%$ students detected that we should develop frequently training combined with new teaching concepts and methods, $22.86 \%$ teachers and $42 \%$ students although know it is important to participate in the course, however they are occupied with the clinical and scientific research, they cannot follow the frequency. Likewise, a small part of doctors $(5.71 \%)$ or students $(6 \%)$ considered there is no need to train, at the time they do the clinical work they teach. $54.29 \%$ teachers considered that whether they can participate in the training course depends on the time since they are occupied with clinical work; $37.14 \%$ felt it is very helpful to participate in the training course. Furthermore, the answers related to the time and frequency requirements for teaching courses among teachers were: regular frequency lectures are essential. I take it seriously to prepare clinical teaching and courses $(51.43 \%)$; How much I can teach depends on my time (14.29\%); Although I think it is essential, however due to the clinical and scientific research cost of time, I cannot ensure the quality (14.29\%); Other feedback identified by interviewers on the survey included the following: The theoretical knowledge is combined with actual clinical work, for a few participants, there is no need to arrange special courses (8.57\%); Although I think it is essential, however, due to the clinical and scientific research cost time, I cannot follow the frequency $(8.57 \%)$. Although I think it does not matter, however, in order to meet the hospital's requirements, I will still follow the frequency, but cannot ensure the quality $(2.86 \%)$.

\subsection{Teaching Appearance}

After the doctor has selected the educational field for their career, we investigated how best to provide the residents with early exposure and training opportunities, and what impact this self-knowledge might have on their career aspirations. As a sensitivity analysis, both $40 \%$ teachers and $30 \%$ students observed teaching is related to the teacher's appearance, teaching state, and speaking tone, or speaking tone can be trained. Then what is the difference between a teaching physician and a general teacher? $74.29 \%$ teachers and $70 \%$ students felt the teaching physician is both a teacher and doctor, who should be equipped with good theoretical and clinical knowledge. $17.14 \%$ teachers and $10 \%$ students indicated teaching physician is more busier than teacher, who should ensure patients' safety during teaching.

\section{Discussion}

Teaching is an integral part of medicine and an essential clinical doctor responsibility, teaching physicians are vital to the graduate medical education. Teaching medical students and residents are key components of a doctor's role. Clearly, it is important that there are clear metrics for teaching excellence attributable to individual academic teaching performance. However, there remained to be explored that how clinical teachers are formally prepared for their teaching role: Who are the ideal teaching physicians? What are their day-to-day duties? What will be the major focus of teaching?

Graduate medical education (GME) defined typical teaching physicians' work including 3 main duties: delivering high quality, safe, and efficient patient care; providing comprehensive physicians-in-training education; and contributing to scholarship. Each of these duties has regulatory aspects with which the teaching physician must comply (1). Teaching physicians involve following these standards, they spend a great deal of time reviewing each patient's medical care accompanied by a resident who observes their activities [4]. The residents even achieve competence through the efforts of teaching physicians, who are mentors, advisors, evaluators, and instructors [1].

Thus, with today's focus on the translation of basic science discoveries into clinical practice, the demand for teaching physicians is growing. Teaching physicians play a central role in advancing residents initiatives and promoting a culture of education among new physicians. An educational teacher pathway is regarded as an independent area of specialization in teaching, which is an option for those who have the potential effort for teaching. In our investigation, $40 \%$ of the interviewers are teaching physicians. $71.43 \%$ teachers and $58 \%$ students felt it is necessary to set the type of teaching physician.

Frequently, those who regarded education as a major component of their careers should combine educational theory and operating skills with simulation teaching. For example, we recommend the first step for any developing surgeon educator is to master one's abilities as a surgeon, followed closely or simultaneously by mastering one's abilities as a teacher. Without the former though, the latter is of no use [5]. Thus, surgeon educators should encompass and excellence in clinical surgery and well integrate the science knowledge and skill acquisition into surgical training and administration because they are not only responsible for developing clinical skills, but also required to become adept at teaching. Additionally, some teaching physicians have specific teaching responsibilities within their subdisciplines. As to the obstetrics and gynecology department, the surgical skills require hand-to-hand teaching, the professional goals of teaching physicians are to advise the best clinical and operative skills to residents in graduate medical education. Therefore, an educational doctor should be equipped with experiences, perspectives, and skills that make them appealing in medical education nationally. In our investigation, we assessed 
career development among doctors' opinions towards teaching physicians, $85.71 \%$ teachers and $61 \%$ students believed doctors cannot teach if they are not equipped with clinical knowledge or surgical skills, thus demonstrated that good teaching was generally conducted along with experienced clinical technology.

However, the challenge all physician investigators face is the increasing burden of clinical activities, particularly with the advent of written medical records [3]. Thus, it is recommended to reduce the clinical workload of teaching physicians. Yet, the teaching physician even faces a number of unique challenges to juggle the demands of clinical care with the time required to perform scientific research or teaching grant funding/awards/publications for their career development. Only $11.43 \%$ teachers and $16 \%$ students thought $80 \%$ of teaching physicians reach the standard of teaching physician requirement, while $71.43 \%$ teachers and $15 \%$ students indicated the percentage is $20 \%$; Another $31.43 \%$ teachers believed $20-40 \%$ of the teaching physicians do not meet the requirements, their purpose of being an educational doctor is to require career promotion, even more $17.14 \%$ teachers regarded the proportion was up to $80 \%$.

The teaching physician is a part-time faculty member, they would even competition for funding from full-time $\mathrm{PhD}$ investigators [3]. When investigators split their time between clinical activities and research, they are not likely to fully meet the target metrics of either full-time researchers or full-time clinicians. We analyzed interviewers' responses to these questions, even $68.57 \%$ teachers and $29 \%$ students from programs thought the appropriate science research proportion of teaching physician should be $20 \%$, which is corresponded with the evaluation for teaching physician's promotion in our hospital. $77.14 \%$ teachers and 54\% students regarded the teaching physician should also be equipped with the scientific research ability to teach students. While another $2.86 \%$ teachers and $7 \%$ students reported although scientific research is important, the reason they choose to be a teaching physician is safe efforts on scientific research.

On the other hand, the hospital also recommended teaching grant funding/awards/publications as the specific promotion requirements for teaching physician. Since it seems the recipients of grant funding were more successful in career promoting than those individuals without grant funding on most career achievement measures, in recent years, there existed the phenomenon that doctors only focus on teaching grant funding/awards/publications, but do not actually do teaching work. As more awards are made, the teaching physician faculty candidates increase career promotion and gain training, observation, or education to be fully successful. Most of us regarded the use of grants as promotion criteria is cruelly unfair, although $80 \%$ of respondents regarded that they should put emphasize on the actual teaching problems rather than take the level of grant funding/awards/publications as the only evaluation, $8.57 \%$ teachers and $6 \%$ students indicated $80 \%$ of teaching physicians only focus on grant funding/awards/publications, while do not actually engage in teaching work. Thus, $28.57 \%$ teachers and $26 \%$ students agreed the purpose to be an educational doctor is for career promotion, so they regarded grant funding/reward/publication is the most important. The reason might be that $71.42 \%$ teachers indicated they are willing to teach, however time is limited, they need to gain grant funding/awards/publications for career promotion instead of daily teaching work. $48.57 \%$ teachers and $46 \%$ students reported there is no other evaluation way, grant funding/awards/publications are fair in evaluation, only $22.86 \%$ teachers and $19 \%$ students believed it is very reasonable.

These above severe situation need to be changed, Mark Hayter believed that only focusing on publishing an internationally excellent paper or winning a large competitive research grant or even successfully supervise $\mathrm{PhD}$ students, ignore actual teaching, might be a dark art worthy of inclusion in the education curriculum [6]. In theory, it would be ideal for all surgical residency applicants to have high technical aptitude - among other nontechnical skills essential for the professional development of an effective surgeon [7]. Development of skills to become a successful medical professional, including professional behavior, goal setting, establishing and maintaining self-esteem, time management, and teamwork [8]. We referenced that perceived professional competence among clinical research coordinators recommended three career constructs including career engagement (CE), career planning (CP), and career satisfaction (CS) were selected to represent career orientation [9]. Career engagement (CE) represented the degree of proactively exhibiting different career behaviors to enhance career development, is of theoretical, organizational, and personal importance [10]. Career planning (CP) represents a facet of career self-management that includes setting clear career-related goals and developing specific strategies needed to achieve those goals [11]. Career satisfaction (CS) refers to an internally defined indicator of career outcomes. Thus, career goals would be relatively accepted within the current institutional culture on the medical curriculum committee if professional development opportunity was offered to teaching physicians. The distant goals focus on technology, educational theory, curriculum development, accreditation, assessment, feedback, quality improvement. Strategic career planning has recently entered the academic curriculum as part of faculty development educational programs.

Efforts to promote career satisfaction, reduce burnout, and facilitate retention need to be expanded beyond early career interventions and may need to be tailored by the career stage. Previous literature has shown that dissatisfied physicians are also at higher risk for professional burnout, which is a potential barrier to successful health care reform [12]. Therefore, we should also provide a way for teaching physicians to report their satisfaction when educating. Compared with those who chose other specialties, the largest influences on those who chose teaching physician were enthusiasm or commitment: what I really want to do fit my domestic circumstances, wanting a career with working conditions. The most recent cohorts have become much more definite about their choice of educational doctor as a career than older cohorts. In our introduction, we showed $25.71 \%$ 
very much willing to work as teaching physician.

Actually, teaching physicians requires regular clinical generation, supervision, and evaluation of training. Frequently, there are many different pathways in medical education. Surgeons assume that training translates them into being an excellent educator, for example, surgical Education for leadership of lesions is intended to serve as a preparation for a career in surgical education. More local opportunities like personal and professional progress can be made in various aspects of educational development. Substantially committee participation and on-line options for specialization could also be important avenues of medical professions education. Teachers faculty can participate in the network resources and conferences through educational development opportunities such as lectures, seminars, workshops, communities, and organizations. A workshop should be conducted for educators which had two objectives: (1) demonstrating educational methods that have been successfully used for teaching in the arena of career development and practice management and (2) developing a professional network to facilitate communication and collaboration toward effective teaching and learning.

Fellowships provide the opportunity to obtain and participate in formal training combined with research and teaching. We assessed the quality of teaching predominantly using evaluations, $57.14 \%$ recommended training, as well as updating the teaching concept and methods. Next, we conducted an investigation about training in teaching, $68.57 \%$ teachers and $47 \%$ students detected that we should develop frequently training combined with new teaching concepts and methods. $51.43 \%$ believed regular frequency lectures are essential, they take seriously to prepare clinical teaching and courses. Yet, current challenges in surgical education include limitations on time for training due to workhour overload and scientific demands, as well as the increasing diversity and complexity of surgical procedures [13]. Likewise, $54.29 \%$ considered that whether they can participate in the training courses depends on time, since they are occupied with clinical work. Another part of interviewers recommended although they think it is essential, however, due to the clinical and scientific research cost of time, they cannot ensure the quality $(14.29 \%)$ or follow the frequency $(8.57 \%)$;

It is through the development of clear, objectively measurable teaching-related outputs and quality evidence that we can be unequivocal when we answer the question; 'who is the best teacher in your school'. Students' feedback and qualitative evaluations of their tutorials should also be available to judge teaching effectiveness and quality in individual promotion and career progression cases [6]. In our investigation, regarding attitude towards integration through teaching, 34.29\% teachers and $79 \%$ students greatly promoted, $57.14 \%$ teachers and $49 \%$ students have a positive effect. A majority of teachers (97.14\%) and students (98\%) believed the most important qualities of an educational doctor were: devoted to the teaching work, good at getting along with students, benefit students from clinical knowledge, while no one thought good at speeches and teaching competitions are the most important quality of an educational doctor. $34.29 \%$ teachers and $79 \%$ students agreed with the statement "Educational physician is important to guide the educational team". Furthermore, $74.29 \%$ teachers and $51 \%$ students indicated teaching physicians should update the teaching concept regularly to bring students new and meaningful teaching experiences. As a sensitivity analysis, $40 \%$ teachers and $30 \%$ students observed teaching is related to the teacher's appearance, teaching state and speaking tone can be trained; $20 \%$ teachers and $40 \%$ students considered theoretical and clinical knowledge is more important. Then what is the difference between a teaching physician and a general teacher? $74.29 \%$ teachers and $70 \%$ students felt the teaching physician is both a teacher and doctor, who should be equipped with good theoretical and clinical knowledge. $17.14 \%$ teachers and $10 \%$ students indicated teaching physician is much busier than no-medical teacher, who should ensure patients' safety during teaching.

\section{Conclusions}

Our study illustrates unique challenges for career teaching physicians. As increasing and increasing career opportunities and challenges arise during the next 10 years, teaching physicians will be better prepared by knowing the basic tenets of strategic career planning. However, this study has a number of limitations. There are areas for further research which are beyond the scope of this study. These could include consideration of differences between graduates of different type of doctors. Additionally, certifications, continuing medical education, course evaluations, awards, and other potentially relevant information could be received later.

\section{Abbreviations}

PBL: Problem-Based Learning, CBL: Case-Based Learning, GME: Graduate medical education, CE: career engagement, $\mathrm{CP}$ : career planning, CS: career satisfaction

\section{Declarations}

\section{Ethics Approval and Consent to Participate}

This study was conducted according to the Declaration of Helsinki. All participants gave written, informed consent to participate and for their identified data to be used in publication.

\section{Availability of Data and Material Statement}

The datasets used and analyzed during the current study are available when provided by the corresponding author.

\section{Authorship}

All the authors have: (1) made an important contribution to the conception and design, acquisition of data, or analysis and interpretation of data in the study; (2) drafted or revised the manuscript critically for intellectual content; and (3) approved the final version of the submitted manuscript. 


\section{Author Contributions}

1. Conception and design: Ye Yang, Wei-Lin Sang, Yan-Li $\mathrm{Li}$, and Su-Fang $\mathrm{Wu}$

2. Administrative support: Qin-Yi Zhang, Jia-Yang Xia

3. Provision of study materials or patients: Xiao-Ling Han, Sheng-Jie Xu

4. Collection and assembly of data: Ye Yang, Qin-Yi Zhang, Jia-Yang Xia

5. Data analysis and interpretation: Ye Yang, Xiao-Ling Han, Sheng-Jie Xu, Xu Zhou

6. Manuscript writing: All authors: Ye Yang, Qin-Yi Zhang, Jia-Yang Xia, Xiao-Ling Han, Sheng-Jie Xu, Wei-Lin Sang, Yan-Li Li, and Su-Fang Wu

7. Final approval of manuscript: All authors: Ye Yang, Qin-Yi Zhang, Jia-Yang Xia, Xiao-Ling Han, Xu Zhou, Sheng-Jie Xu, Wei-Lin Sang, Yan-Li Li, and Su-Fang Wu

\section{Competing Interests}

The authors declare that they have no competing interests.

\section{Footnote}

Ethical statement: The authors are accountable for all aspects of the work in ensuring that questions related to the accuracy or integrity of any part of the work are appropriately investigated and resolved.

\section{Funding}

This study was supported by the Ideological and Political Education of Shanghai Jiao Tong University School of Medicine (SZ1917) in collection, analysis, and interpretation of data as well as in writing the manuscript. This study was also supported by Ideological and Political Courses of Shanghai Jiao Tong University School of Medicine in the design of the study and collection, analysis, and interpretation of data.

\section{Highlights}

1. It is important to administrate the teaching environment and policies to provide career chances for teaching physicians.

2. Evaluations were made for teaching activity and quality about personal strategic planning of the manuscript and funds focusing on professional development.

3. Clinical training provides a foundation of the course in medical education, where teachers gather to participate in sessions and workshops.

\section{References}

[1] Steinmann AF, Dy NM, Kane GC, Jr JIK, Silbiger S, Sharma N, Rifkin W. The Modern Teaching Physician-Responsibilities and Challenges: An APDIM White Paper. Am J Med. 2009; 122 (7): 692-697.

[2] Alberts B, Kirschner MW, Tilghman S, Varmus H. Rescuing US biomedical research from its systemic flaws. Proc Natl Acad Sci U S A. 2014; 111 (16): 5773-5777.

[3] McKinney, E. R. The Daunting Career of the PhysicianInvestigator. Acad Med. 2018; 93 (4): 517.

[4] Song KH, Nguyen DR, Dietrich EJ, Powers JE, Barrett JP. Career Satisfaction of Military Medical Officers. Mil Med. 2019 Oct 28. pii: usz327. doi: 10.1093/milmed/usz327. [Epub ahead of print].

[5] Terhune KP, Joshi ART, Choi J. Career advancement in surgical education. Surgery 2019 Oct 14. pii: S0039-6060 (19) 30665-8. doi: 10.1016/j.surg.2019.07.036. [Epub ahead of print]

[6] Hayter M. Academic nursing in the UK: The case for parity of rigour, transparency and level of challenge between research and teaching career tracks. J Adv Nurs. 2019; 75 (7): 1377-1378.

[7] Panait L, Larios JM, Brenes RA, Fancher TT, Ajemian MS, Dudrick SJ, et al. Surgical Skills Assessment of Applicants to General Surgery Residency. J Surg Res. 2011; 170 (2): 189-194.

[8] Lloyd JW, Bristol DG, Draper DD, Mcmanus JP, Bonvicini KA. Models for Teaching Career Development and Practice Management. J Vet Med Educ. 2014; 31 (2): 168-174.

[9] Rojewski JW, Choi I, Hill JR, Ko Y, Walters KL, Kwon S, et al. Career orientation and perceived professional competence among clinical research coordinators. J Clin Transl Sci. 2019; 3 (5): $234-244$

[10] Hirschi A, Freund PA. Career Engagement: Investigating Intraindividual Predictors of Weekly Fluctuations in Proactive Career Behaviors. The Career Development Quarterly. 2014; 62 (1): 5-20.

[11] Ng T, Eby L, Sorensen K, Feldman D. Predictors of objective and subjective career success: A meta-analysis. Personnel Psychology. 2005; 58 (2): 367-408.

[12] Dyrbye LN, Shanafelt TD. Physician Burnout: A Potential Threat to Successful Health Care Reform. JAMA. 2011; 18; 305 (19): 2009-2010.

[13] Phoebe, Mitchell, Stuart, Ostby, Kristin, Mara, et al. Career Interest and Psychomotor Aptitude Among Medical Students. $J$ Surg Educ. 2019; 76 (6): 1526-1533. 